\title{
Technical note: Comparative analyses of the quality and yield of genomic DNA from invasive and noninvasive, automated and manual extraction methods
}

\author{
C. Foley, ${ }^{\star}$ C. O’Farrelly, † and K. G. Meade ${ }^{\star 1}$ \\ ${ }^{*}$ Animal and Grassland Research and Innovation Centre, Teagasc, Grange, Co. Meath, Ireland \\ †Comparative Immunology Group, School of Biochemistry and Immunology, Trinity College Dublin, Ireland
}

\begin{abstract}
Several new automated methods have recently become available for high-throughput DNA extraction, including the Maxwell 16 System (Promega UK, Southampton, UK). The purpose of this report is to compare automated with manual DNA extraction methods, and invasive with noninvasive sample collection methods, in terms of DNA yield and quality. Milk, blood, and nasal swab samples were taken from 10 cows for DNA extraction. Nasal swabs were also taken from 10 calves and semen samples from 15 bulls for comparative purposes. The Performagene Livestock (DNA Genotek, Kanata, Ontario, Canada) method was compared with similar samples taken from the same animal using manual extraction methods. All samples were analyzed using both the Qubit Quantification Platform (Invitrogen Ltd., Paisley, UK) and NanoDrop spectrophotometer (NanoDrop Technologies, Inc., Wilmington, DE) to accurately assess DNA quality and quantity. In general, the automated Maxwell 16 System performed best, consistently yielding high quantity and quality DNA across the sample range tested. Average yields of 28.7, 10.3 , and $19.2 \mu \mathrm{g}$ of DNA were obtained from $450 \mu \mathrm{L}$ of blood, $400 \mu \mathrm{L}$ of milk, and a single straw of semen, respectively. The quality of DNA obtained from buffy coat and from semen was significantly higher with the automated method than with the manual methods (260/280 ratio of 1.9 and 1.8, respectively). Centrifugation of whole blood facilitated the concentration of leukocytes in the buffy coat, which significantly increased DNA yield after manual extraction. The Performagene method also yielded 18.4 and $49.8 \mu \mathrm{g}$ of high quality (260/280 ratio of 1.8) DNA from the cow and calf nasal samples, respectively. These results show the advantages of noninvasive sample collection and automated methods for high-throughput extraction and biobanking of high quality DNA.
\end{abstract}

Received November 4, 2010.

Accepted March 4, 2011.

${ }^{1}$ Corresponding author: Kieran.meade@teagasc.ie
Key words: Maxwell, Performagene, DNA extraction, buffy coat

\section{Technical Note}

Large-scale genomic analyses are now becoming more common to find genes controlling complex traits. For sufficient power to detect and to validate gene associations, thousands of individual animals are usually required for genotyping (Mai et al., 2010; Sahana et al., 2010). It is critical, therefore, that a robust highthroughput method for DNA extraction is selected. Recently, several new technologies have become available for DNA extraction, using automated and semi-automated technologies and the aim of the current study was to evaluate these novel methods for noninvasive sample collection and DNA extraction and compare DNA yield and quality to conventional manual extraction methods. Conventional manual methods are widely published for DNA extraction from specific cells, tissues, and fluids (blood, milk, and semen; Murphy et al., 2002; Hawken et al., 2006; Psifidi et al., 2010). However, manual protocols are often more time-consuming and can produce less consistent results than automated methods. The Maxwell 16 System (Promega UK, Southampton, UK) is an automated DNA extraction platform that can be used to extract DNA from a diverse range of tissues, including fresh and frozen blood, semen, and ear punches. Performagene Livestock is another recently launched method for extracting DNA from nasal cells (DNA Genotek, Kanata, Ontario, Canada). This method is easy to use, does not require blood sampling or extensive sample processing, and therefore, is suitable for sampling large numbers of animals rapidly.

To compare invasive and noninvasive, and automated and manual sampling methods, 10 suckler beef cows and calves from the Teagasc beef research farm (Co. Meath, Ireland) were used. Milk samples were collected from a random teat into a $50-\mathrm{mL}$ sterile collection tube. This sample was subsequently divided into two 25-mL tubes - one for each DNA extraction method. Subsequently, peripheral blood was collected using two 
9-mL $\mathrm{K}_{2}$ EDTA Vacutainer blood-collection tubes (BD Diagnostics, Oxford, UK) by jugular venipuncture. These samples were inverted to mix and prevent clotting. Finally, due to the less docile nature of beef cows compared with dairy cows, animals were restrained in the cattle crush using nose tongs and nasal swabs were then easily collected. Separately, semen straws were sourced from the National Cattle Breeding Centre (Co. Meath, Ireland).

Four procedures (a-d) were used for DNA extraction, as shown in Figure 1: (a) Maxwell 16 System (Promega UK), automated method: the Maxwell System was set up as described by the manufacturer. Cartridges were selected according to tissue type-for blood buffy coat, a blood DNA purification kit cartridge was used (catalog no. AS1010), and for whole milk and semen, the tissue DNA purification cartridge was used (catalog no. AS1030). Briefly, buffy coat, or whole milk pellet (milk samples were centrifuged for 5 min at 2,200 $\times g$ at room temperature, and the supernatant and fat layer were removed and discarded using a sterile Pasteur pipette) was added to well number 1 of each cartridge. Cartridges were loaded into the Maxwell System, seals were removed and plungers were added to well 7. After addition of $400 \mu \mathrm{L}$ of elution buffer, the blue elution tubes were also loaded onto the platform. The correct program on the Maxwell System was selected and DNA was eluted after approximately $40 \mathrm{~min}$. The DNA was subsequently transferred to a microcentrifuge tube for storage at $-20^{\circ} \mathrm{C}$. The procedure for DNA extraction from semen ( $\mathrm{n}=5$ samples) required an initial overnight incubation step before automatic processing as described above. Each semen straw was emptied into a 1.5-mL tube containing $1 \mathrm{~mL}$ of PBS (pH 7.4). To pellet the sperm, tubes were centrifuged for $5 \mathrm{~min}$ at $5,000 \times g$ at room temperature. The supernatant was removed and the sperm was re-suspended in $1 \mathrm{~mL}$ of PBS. The samples were then centrifuged for $5 \mathrm{~min}$ at $5,000 \times g$ at room temperature and the supernatant removed. The pellet was subsequently lysed by adding $450 \mu \mathrm{L}$ of extraction buffer, $10 \mathrm{~m} M$ Tris $\mathrm{pH}$ 8.0, 10 $\mathrm{m} M$ EDTA $\mathrm{pH}$ 8.0, $1 \%$ SDS, and $100 \mathrm{~m} M \mathrm{NaCl}$, and warmed to $60^{\circ} \mathrm{C}$. Fifty microliters of $0.5 \mathrm{M}$ dithiothreitol and $10 \mu \mathrm{L}$ of proteinase $\mathrm{K}$ solution $(20 \mathrm{mg} / \mathrm{mL})$ were added to the samples, which were incubated at $60^{\circ} \mathrm{C}$ overnight. Samples were loaded into the Maxwell System and subsequently eluted in $300 \mu \mathrm{L}$ of elution buffer; (b) manual method-whole blood: $300 \mu \mathrm{L}$ of proteinase $\mathrm{K}$ mixture was added $(0.5 M$ EDTA, $[\mathrm{pH}$ 8.0], $20 \%$ SDS, $20 \mathrm{mg} / \mathrm{mL}$ Proteinase K) to $300 \mu \mathrm{L}$ of whole blood. The mix was incubated overnight on a heating block at $50^{\circ} \mathrm{C}$. Then, $3.5 \mathrm{~mL}$ of saturated $\mathrm{NaCl}$ solution was added and each sample was vortexed vigorously for 30 to $60 \mathrm{~s}$. Two volumes of $95 \%$ ethanol was added and contents were inverted gently to precipitate the DNA. After overnight storage at $-20^{\circ} \mathrm{C}$, the solution was centrifuged at $12,000 \times g$ for $15 \mathrm{~min}$. Then, $400 \mu \mathrm{L}$ of DNA (and the surrounding liquid) was removed to a $1.5-\mathrm{mL}$ microcentrifuge tube. After centrifugation at $12,000 \times g$ for $15 \mathrm{~min}$, the pellet was washed with $70 \%$ ethanol, and dried on a heating block at $55^{\circ} \mathrm{C}$ for $5 \mathrm{~min}$. Finally, the pellet was dissolved in $500 \mu \mathrm{L}$ of Tris and EDTA (TE) and allowed dissolve overnight at room temperature. Semen samples ( $\mathrm{n}=5$ straws) were pelleted and washed in PBS as described above, before extraction was carried out using the same extraction method. Blood buffy coat was prepared by spinning whole blood, in a Vacutainer, at $2,000 \times g$ for $20 \mathrm{~min}$ at room temperature to separate the blood into its plasma, leukocyte, and erythrocyte fractions. The buffy coat was removed and extracted as described above; (c) manual method-milk: whole milk DNA was extracted using a previously published protocol (Murphy et al., 2002). Subsequently, a DNA cleanup was performed to remove cellular debris from milk tissue samples (Sambrook and Russell, 2001). Semen samples ( $\mathrm{n}=5$ straws) were pelleted and washed in PBS as described above, before extraction was then carried out using the same manual method for milk; (d) Performagene method - nasal swabs: after rotation of the sponge applicator for $5 \mathrm{~s}$ within the nostril of each cow or calf, the applicator was returned to the container, closed tightly, and shaken vigorously in the lysis and stabilization solution. Tubes were then stored at room temperature. In preparation for PCR, samples were purified as recommended by the manufacturer. Briefly, tubes were incubated at $50^{\circ} \mathrm{C}$ overnight and, subsequently, the sponge applicator was squeezed inside each tube to recover maximum solution. To $500 \mu \mathrm{L}$ of the DNA solution in a $1.5-\mathrm{mL}$ microcentrifuge tube, $20 \mu \mathrm{L}$ of purifier solution was mixed in and incubated for $10 \mathrm{~min}$ on ice. After centrifugation at $15,000 \times g$ for $5 \mathrm{~min}, 25 \mu \mathrm{L}$ of $5 \mathrm{M} \mathrm{NaCl}$ was added to $500 \mu \mathrm{L}$ of the clear supernatant in a fresh tube. Six hundred microliters of $100 \%$ ethanol was then added and the tube inverted several times. After 10 min of incubation at room temperature, the samples were centrifuged for 2 min at $15,000 \times g$. Supernatant was discarded and the pellet was washed with $250 \mu \mathrm{L}$ of $70 \%$ ethanol. After carefully removing the ethanol, DNA was vortexed for $5 \mathrm{~s}$ and dissolved in $100 \mu \mathrm{L}$ of TE buffer overnight.

The DNA quality (260/280 ratio) was assessed using a NanoDrop ND-1000 UV-Vis Spectrophotometer (NanoDrop Technologies Inc., Wilmington, DE). The DNA quantity was assessed using 2 commonly used laboratory methods - a NanoDrop and a Qubit Quantitation Platform (Invitrogen, Paisley, UK). The spectrophotometer calculates concentration based on 


\section{Sample collection}

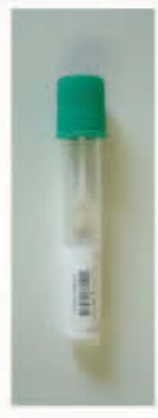

Nasal cells, blood, milk and semen samples

4 Methods

Quantity and

quality analysis

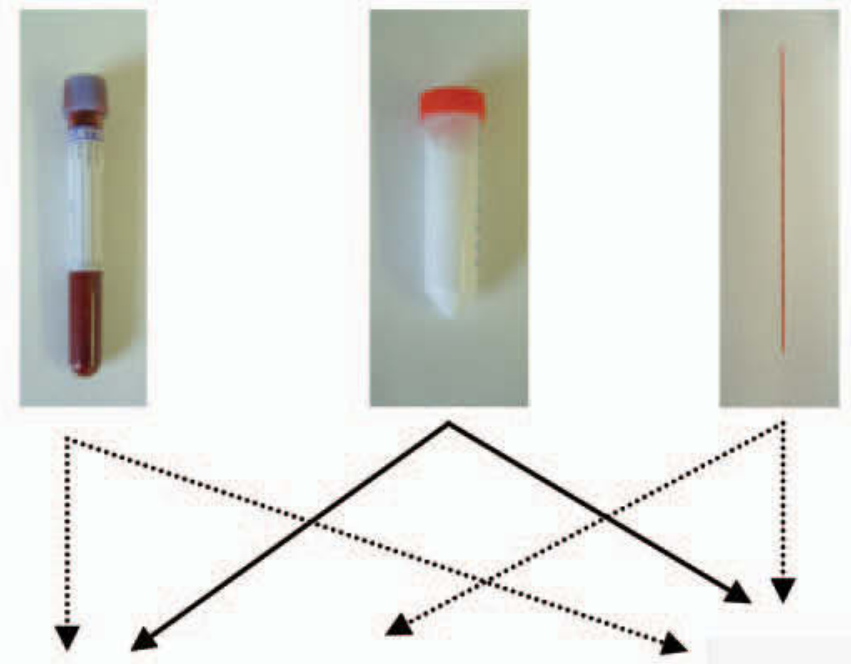

Manual extraction methods
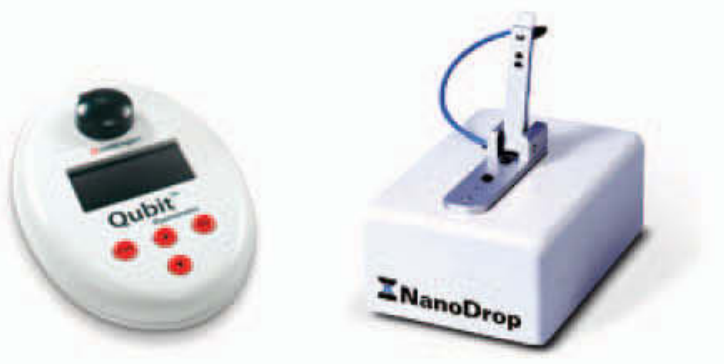

PCR and biobanking

Figure 1. Flow diagram showing procedures used for DNA extraction from different tissues. Color version available in the online PDF.

absorbance, whereas the Qubit Quantitation Platform calculates concentration based on the fluorescence of the Quant-It reagent, which binds to double-stranded DNA. Yield measures from the NanoDrop and Qubit were generally consistent between both analytical methods (Figure 2). Statistical analysis of the results was carried out using nonparametric Mann-Whitney U tests, as implemented in version 5.01 of StatView (SAS Institute Inc., Cary, NC).

The different DNA extraction methods yielded DNA of varying quality and quantity from the various tissue types; the average time taken, DNA yields, and quality are shown in Table 1. In general, the automated Maxwell System performed best, consistently yielding high quantity and quality DNA across the sample range tested (Figure 3 and Table 1). An important finding is that centrifugation of Vacutainers containing whole blood facilitated the concentration of leukocytes in the buffy coat, which significantly increased DNA yield $(P$ $<0.05)$. An average yield of $28.7 \mu \mathrm{g}$ of genomic DNA was obtained from $450 \mu \mathrm{L}$ of blood buffy coat $(\mathrm{n}=10$ animals) using the Maxwell System. Although the resulting yield was better when using the manual method for blood buffy coat $(41.8 \mu \mathrm{g})$, this difference was not statistically significant $(P>0.05)$. The DNA and PCR quality was significantly higher with the automated method (average 260/280 ratio of 1.9 against 1.6, $P=$ 0.0013).

The Maxwell System also outperformed other methods in extracting DNA from somatic cells in milk (n $=10$ animals), and compared favorably in terms of processing time and PCR quality (Table 1). From 400 


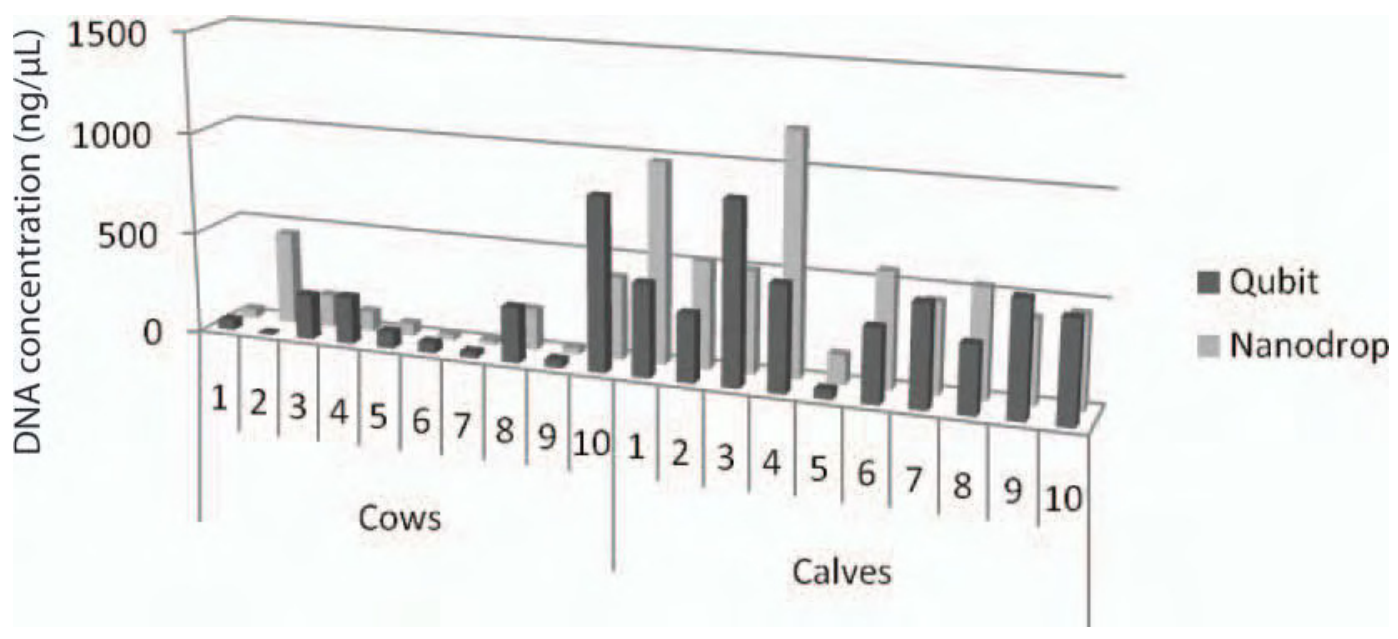

Figure 2. DNA extraction from nasal swabs was performed using the Performagene (DNA Genotek, Kanata, Ontario, Canada) method from 10 cows and 10 calves. DNA concentrations were measured using the Qubit Quantification Platform (Invitrogen Ltd., Paisley, UK) and NanoDrop (NanoDrop Technologies Inc., Wilmington, DE) for comparative analysis. The average volume of DNA recovered was between 100 and $110 \mu \mathrm{L}$.

$\mu \mathrm{L}$ of milk, an average of $10 \mu \mathrm{g}$ of genomic DNA was obtained with the Maxwell System, which is approximately equivalent to $3.5 \mu \mathrm{g}$ from $100 \mu \mathrm{L}$ of milk using the published manual method (procedure 3, Table 1). Quality however, was higher with the manual method (average 260/280 ratio of 1.7) compared with the automated method (average 260/280 ratio of 1.4 ), although this difference was not significant $(P>0.05)$ either. The Maxwell System was again a significantly superior method for extraction of DNA from semen, yielding, on average, $19.2 \mu \mathrm{g}$ of DNA from a single straw $(P<0.05$, $\mathrm{n}=5)$. From similar input quantities, only $1 \mu \mathrm{g}$ was obtained using the manual blood extraction method (procedure 2) and $5.9 \mu \mathrm{g}$ using the manual milk extraction procedure (procedure 3 ). The DNA quality was also significantly higher at 1.8 (260/280 ratio) for the automated method compared with 1.3 and 0.9 for the 2 manual methods ( $P=0.009$; Table 1$)$. Of note, however, is that semen samples from different bulls were used for each extraction method and so results may not be directly comparable.

As an alternative to invasive methods for genomic DNA collection, the Performagene method (DNA Genotek) was also analyzed in this study. The Performa-

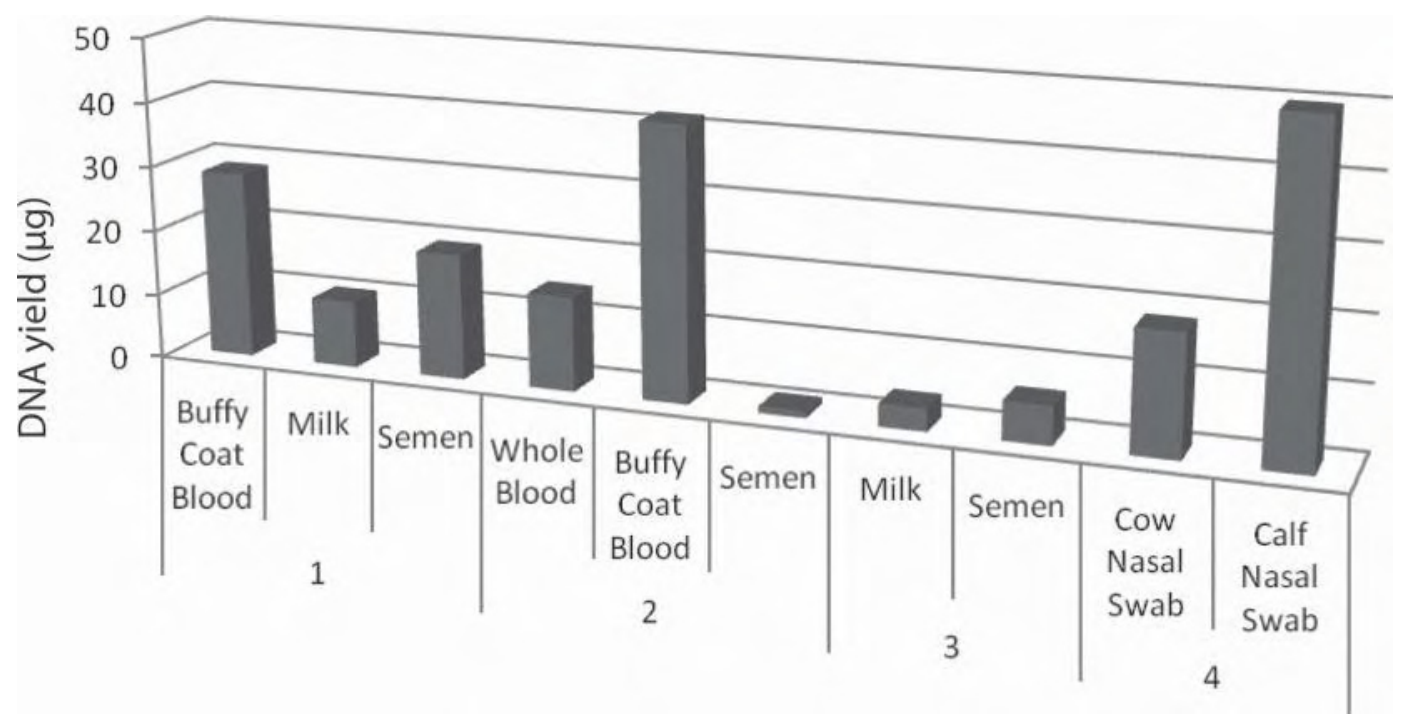

Figure 3. DNA yields measured using 4 different DNA extraction procedures from different tissues. Procedure 1: Maxwell System (Promega UK, Southampton, UK), automated method; procedure 2: manual method—blood; procedure 3: manual method — milk; procedure 4: Performagene (DNA Genotek, Kanata, Ontario, Canada) method-nasal swabs. Total DNA yield $=[$ elution volume $\times$ DNA quantity using the Qubit Quantification Platform (Invitrogen Ltd., Paisley, UK)]. Blood, milk, and cow nasal swabs were collected from the same animals (n = 10). 
Table 1. Comparison of average time taken, yield, and quality of 4 different DNA extraction procedures across a range of cattle tissues

\begin{tabular}{|c|c|c|c|c|c|c|c|c|c|c|}
\hline \multirow[b]{2}{*}{ Tissue } & \multirow[b]{2}{*}{ Procedure $^{1}$} & \multirow[b]{2}{*}{$\begin{array}{c}\text { Input } \\
(\mu \mathrm{L})\end{array}$} & \multirow[b]{2}{*}{$\begin{array}{l}\text { Hands-on } \\
\text { time (min) }\end{array}$} & \multicolumn{2}{|c|}{ NanoDrop } & \multirow{2}{*}{$\begin{array}{c}\text { Qubit } \\
\text { concentration } \\
(\mathrm{ng} / \mu \mathrm{L})\end{array}$} & \multirow{2}{*}{$\begin{array}{l}\text { Eluted } \\
\text { volume } \\
(\mu \mathrm{L})\end{array}$} & \multicolumn{2}{|c|}{ Qubit } & \multirow[b]{2}{*}{$\begin{array}{c}\text { PCR quality } \\
(\%)\end{array}$} \\
\hline & & & & $\begin{array}{c}260 / 280 \\
\text { ratio }\end{array}$ & $\begin{array}{l}\text { Concentration } \\
\quad(\mathrm{ng} / \mu \mathrm{L})\end{array}$ & & & $\begin{array}{l}\text { Total yield } \\
\quad(\mu \mathrm{g})\end{array}$ & $\mathrm{SD}$ & \\
\hline Buffy coat blood & 1 & 450 & 65 & $1.9^{\mathrm{ab}}$ & 158.5 & 179.2 & 160 & 28.7 & 9.0 & 100 \\
\hline Milk & & 400 & 50 & 1.4 & 32.4 & 41 & 250 & 10.3 & 15.2 & 90 \\
\hline Semen & & 1 straw & $75^{2}$ & $1.8^{\text {as }}$ & 113.5 & 101.3 & 190 & $19.2^{\mathrm{ad}}$ & 8.4 & 100 \\
\hline Whole blood & 2 & 300 & $50^{3}$ & 1.7 & 29.1 & 31.5 & 460 & $14.5^{\text {by }}$ & 34.5 & 100 \\
\hline Buffy coat blood & & 450 & $65^{3}$ & $1.6^{\mathrm{bb}}$ & 158.2 & 92.9 & 450 & $41.8^{\mathrm{bz}}$ & 7.5 & 90 \\
\hline Semen & & 1 straw & $70^{3}$ & $1.3^{\mathrm{bs}}$ & 56.2 & 9.8 & 100 & $1.0^{\mathrm{bd}}$ & 1.1 & $\mathrm{NA}^{4}$ \\
\hline Milk & 3 & 100 & $215^{3}$ & 1.7 & 53.7 & 69.2 & 50 & 3.5 & 3.8 & 70 \\
\hline Semen & & 1 straw & $65^{2}$ & $0.9^{\mathrm{cs}}$ & 261.5 & 42.1 & 140 & $5.9^{\mathrm{cd}}$ & 4.2 & NA \\
\hline Cow nasal swab & 4 & 500 & $45^{3}$ & 1.8 & 150.9 & 183.9 & 100 & $18.4^{\mathrm{dn}}$ & 26.3 & 90 \\
\hline Calf nasal swab & & 500 & $45^{3}$ & 1.8 & 571.9 & 453 & 110 & $49.8^{\mathrm{en}}$ & 25.7 & 80 \\
\hline
\end{tabular}

${ }_{\mathrm{ab}, \mathrm{bb}}$ Values with differing superscripts denote a significant difference in buffy coat DNA quality between procedures $(P<0.05)$.

${ }^{\text {as,bs,cs }}$ Values with differing superscripts denote a significant difference in semen DNA quality between source samples $(P<0.05)$.

${ }^{\text {ad,bd,cd } V a l u e s ~ w i t h ~ d i f f e r i n g ~ s u p e r s c r i p t s ~ d e n o t e ~ a ~ s i g n i f i c a n t ~ d i f f e r e n c e ~ i n ~ s e m e n ~ D N A ~ c o n c e n t r a t i o n ~ b e t w e e n ~ p r o c e d u r e s ~}(P<0.05)$.

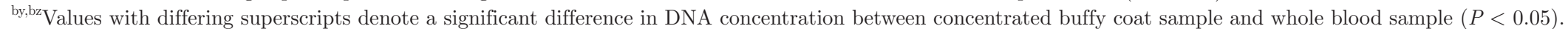

${ }^{\mathrm{dn}, \mathrm{en}}$ Values with differing superscripts denote a significant difference in nasal DNA concentration between source samples $(P<0.05)$. Lack of superscript denotes nonsignificant $(P$ $>0.05)$ differences between source samples or procedures.

${ }^{1}$ Procedure 1: Maxwell System (Promega UK, Southampton, UK), automated method; procedure 2: manual method-blood; procedure 3: manual method—milk; procedure 4: Performagene (DNA Genotek, Kanata, Ontario, Canada) method - nasal swabs. Total DNA yield $=$ [elution volume $\times$ DNA quantity using the Qubit Quantification Platform (Invitrogen Ltd., Paisley, UK)]. Samples from the same 10 individual cows and calves were used for each DNA extraction procedure, except for semen DNA extraction, where dif¿ ferent bull samples were used.

@ One overnight digestion step.

을 ${ }^{3}$ Two overnight DNA incubation/digestion/dissolve steps.

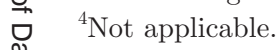



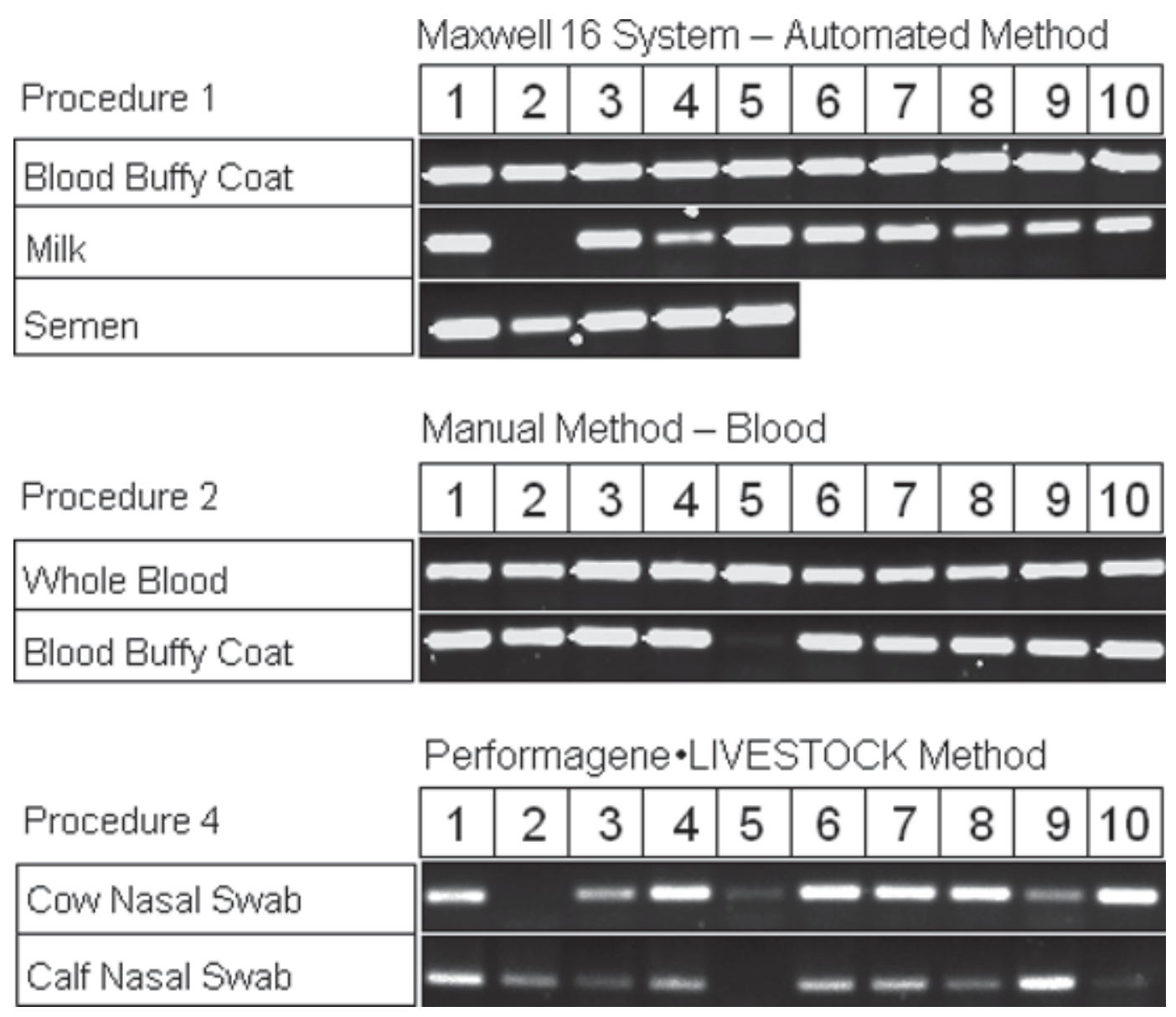

Figure 4. DNA quality assessed by PCR and gel electrophoresis. Procedure 1: Maxwell System (Promega UK, Southampton, UK), automated method; procedure 2: manual method—blood; and procedure 4: Performagene (DNA Genotek, Kanata, Ontario, Canada) method. Blood, milk, and cow nasal swabs were collected from the same animals $(\mathrm{n}=10)$. Individual bulls were used for 5 semen samples and DNA was also collected using nasal swabs from an additional 10 individual calves.

gene method uses nasal swabs to collect DNA from nasal cells. For comparative analysis, samples were collected from 10 cows and 10 calves on the same farm. Genomic DNA yields were very high quality $(260 / 280$ ratio of 1.8) and quantity, with 18.4 and $49.8 \mu \mathrm{g}$ from the cow and calf nasal samples, respectively $(\mathrm{n}=10 /$ group, Table 1). The reason for the significantly $(P$ $=0.005)$ and consistently higher yield in calf samples shown in Figure 2 is unknown, but may be due to the higher number of nasal leukocytes and epithelial cells in calves. No significant difference in DNA quality was detected between samples taken from cows and calves $(P$ $>0.05$ ). All samples were subjected to PCR to amplify the $A C T B$ gene, and test the efficiency of amplification, as a measure of DNA sample purity and quality (Figure 4).

Multiple manual methods are available for extraction of DNA. The optimal protocol for use in a particular laboratory will vary depending on sample type, sample number, cost per sample, facilities for sample collec- tion, and the quality of DNA required post-extraction. Blood, milk, and nasal samples were taken from the same 10 animals in this study and results demonstrate that blood buffy coat gives the highest total yield of genomic DNA. Nasal samples taken from calves are the only exception to this, yielding almost $50 \mu \mathrm{g}$ of DNA, on average. For semen, the automated method is superior to the manual blood method, yielding over 3 times the concentration of DNA from the same sample volume. For high-throughput analysis, it helps if sample yield and quality are consistent across samples taken, often from thousands of individuals necessary for genomewide association studies (Mai et al., 2010, Sahana et al., 2010). Results from the present study suggest that automated DNA extraction has benefits in terms of consistent yield and DNA quality both across diverse sample types and across individual animal samples. Results presented here are comparable to a recent study comparing 3 different automated whole blood DNA extraction procedures and which advocates the use of such 
methods toward removing the limiting step of manual DNA extraction methods for molecular-based diagnostic tests (Lee et al., 2010). The potential benefits from using an automated DNA extraction method are manifested particularly when dealing with large numbers of samples and where purity is important for long-term storage (biobanking). Although the cost for equipment (Maxwell System) and sample kit costs (Maxwell and Performagene method) will increase the cost of extraction over manual methods, they do achieve a decrease in hands-on time and labor costs, and worker safety in the laboratory, reproducibility of results, and quality of the DNA extracted is increased (Tan and Yiap, 2009).

Ideally, it would be preferable to collect samples by noninvasive means for the extraction of DNA, especially on a farm-wide scale. Milk, nasal, and semen samples provide such a noninvasive opportunity for sample collection. Results obtained in this study indicate that the Maxwell System yielded the best quality of DNA from milk and semen, which can be used in downstream PCR applications. Milk samples are obviously restricted to lactating animals and can vary considerably in cell number between animals (Lipkin et al., 1993) and with infection status (such as mastitis; Murphy et al., 2002), and therefore, may not be seen as the most attractive for consistent DNA yield. Contaminating compounds, including fat, complicate extraction and may also interfere with downstream processes (Wilson, 1997). In this context, and in terms of labor, minimal sample processing on farm, and its noninvasive process, the Performagene method has particular utility. Sample collection using nasal swabs can be applied to all cattle regardless of developmental age or sex. It is noninvasive and, therefore, has animal welfare benefits. Furthermore, the contained swab means that cleanliness and sample stability is maintained, especially when sample collection is on-farm. The combined results from this study demonstrate the advantages of automated and noninvasive methods for high-throughput extraction of high-quality DNA.

\section{ACKNOWLEDGMENTS}

The authors thank the farm staff in Teagasc, Grange (Co. Meath, Ireland) for assistance with sample collection. Furthermore, the donation of semen straws from the National Cattle Breeding Centre is also greatly appreciated. Performagene Livestock DNA collection tubes were kindly supplied by DNA Genotek (Kanata, Ontario, Canada). This work was funded by a Teagasc Walsh Fellowship to C. Foley (R6083).

\section{REFERENCES}

Hawken, R. J., J. A. Cavanagh, J. R. Meadows, M. S. Khatkar, Y. Husaini, K. R. Zenger, S. McClintock, A. E. McClintock, and H. W. Raadsma. 2006. Technical note: Whole-genome amplification of DNA extracted from cattle semen samples. J. Dairy Sci. 89:2217-2221.

Lee, J.-H., Y. Park, J. R. Choi, E. K. Lee, and H.-S. Kim. 2010. Comparisons of three automated systems for genomic DNA extraction in a clinical diagnostic laboratory. Yonsei Med. J. 51:104-110.

Lipkin, E., A. Shalom, H. Khatib, M. Soller, and A. Friedmann. 1993. Milk as a source of deoxyribonucleic acid and as a substrate for the polymerase chain reaction. J. Dairy Sci. 76:2025-2032.

Mai, M. D., G. Sahana, F. B. Christiansen, and B. Guldbrandtsen. 2010. A genome-wide association study for milk production traits in Danish Jersey cattle using a $50 \mathrm{~K}$ single nucleotide polymorphism chip. J Anim. Sci. 88:3522-3528.

Murphy, M. A., M. R. Shariflou, and C. Moran. 2002. High quality genomic DNA extraction from large milk samples. J. Dairy Res. 69:645-649.

Psifidi, A., C. I. Dovas, and G. Banos. 2010. A comparison of six methods for genomic DNA extraction suitable for PCR-based genotyping applications using ovine milk samples. Mol. Cell. Probes 24:93-98.

Sahana, G., B. Guldbrandtsen, C. Bendixen, and M. S. Lund. 2010. Genome-wide association mapping for female fertility traits in Danish and Swedish Holstein cattle. Anim. Genet. 41:579-588.

Sambrook, J., and D. W. Russell. 2001. Molecular Cloning: A Laboratory Manual. 3rd ed. Cold Spring Harbor Laboratory Press, Cold Spring Harbor, NY.

Tan, S. C., and B. C. Yiap. 2009. DNA, RNA, and protein extraction: The past and the present. J. Biomed. Biotechnol. 2009:574398.

Wilson, I. G. 1997. Inhibition and facilitation of nucleic acid amplification. Appl. Environ. Microbiol. 63:3741-3751. 